\title{
Roentgenoanatomy of the hip joint following reconstructive intervention in children with spastic cerebral palsy
}

\author{
A.D. Tomov, M.P. Teplenky, A.M. Aranovich, G.M. Chibirov, D.A. Popkov
}

National Ilizarov Medical Research Centre for Orthopaedics and Traumatology, Kurgan, Russian Federation

\begin{abstract}
Objective Explore changes in roentgenoanatomical parameters of the pediatric hip joint following multilevel reconstructive surgeries performed for CP patients in combination with derotation varus osteotomy (DVO) alone or DVO and acetabuloplasty (AP). Material and methods The study included 49 children (30 GMFCS level IV and 19 GMFCS level V patients). Either DVO ( $n=28,44$ joints, mean age $6.98 \pm 2.2$ years $)$ or DVO and AP $(n=21,38$ oints, mean age $7.0 \pm 2.04$ years $)$ were produced in combination with multilevel reconstructive surgeries to eliminate contractures of the knee and ankle joints and correct foot deformities. The acetabular angle, the Reimers' index, the acetabular depth ratio (ADR), the Wiberg center-edge angle were measured preoperatively, straight after surgery and at 1, 2, 3 years postsurgery. Results Normal relationship between the femoral head and acetabulum persisted at a long-term follow-up. The parameters evaluating acetabular morphology (Wiberg angle, AI and ADR) were shown to improve or remain stable. The mean annual increase in the Reimers' index was not more than $3 \%$ after DVO and not more than $2 \%$ following DVO and AP. A reverse statistically significant correlation was detected between the AI and Wiberg angle after DVO alone or DVO combined with AP throughout the observation period. This sort of correlation facilitated beneficial development of the operated hips at a long term following reconstructive interventions. Moderate correlation was observed in changed AI values after DVO at 3 years postsurgery and changes in the Wiberg angle at three-year observation comparing relative measurement changes and the age when surgery was performed. Age appeared to have a minor effect on the development of the hip following multilevel procedures produced for the cohort of patients. Conclusion Appropriate conditions should be provided for normal development of the hip to address hip dislocation using growth-remaining potential and remodeling the articular ends. Single-event multilevel surgery involving hip reconstruction and addressing knee and ankle contractures is practical for providing favorable conditions for postural management and passive verticalization of patients to maintain axial loading on the limbs.
\end{abstract}

Keywords: hip dislocation, cerebral palsy, single-event multilevel orthopedic surgery

\section{INTRODUCTION}

The reported incidence of hip dislocation and subluxation in children with cerebral palsy $(\mathrm{CP})$ has ranged from $2.6 \%$ to $75 \%$ [1-4]. However, children who are unable to stay in an upright posture and ambulate are at risk for developing hip displacement or dislocation in 60-90\% [5]. Hip dislocation may lead to notable functional impairments affecting the ability to sit, keep upright posture and predispose to early coxarthrosis and severe pain, challenges in socialization and participation [3, 6-9]. Current concepts on hip reconstructive surgeries in children with CP have developed widely accepted indications including optimal age and recommended surgical approaches (derotation varus osteotomy (DVO) of the proximal femur, angular stable plating combined with acetabuloplasty (AP) or without pelvic intervention [10-17]. CP children need to continue with follow up to monitor the development and growth of the hip joint after hip reconstruction. Several radiographic measurements have been reported, but the most widely used are Reimer's migration index, centeredge (CE) angle of Wiberg and the acetabular index (AI) with the mean yearly increase in the values $[10$, 18-20]. In the unfavorable scenario, the recurrence of hip displacement or dislocation after reconstructive surgery can range between 5.6 to $25.7 \%$ [18, 21-23]. However, there are findings in the literature focusing on outcomes of interventions and the development of the hip joint following isolated hip reconstruction neglecting concurrent correction of contractures of the knee and ankle joints and foot deformities that would have facilitated comprehensive postural management and passive support to lower limbs [24-27]. And outcome assessment of reconstructive procedures is not reported separately for the groups of patients who undergo standalone DVO and DVO combined with AP [28]. Changes in radiological and anatomical parameters of the hip joint following reconstructive multilevel interventions have been explored separately in DVO group and DVO+AP group.

[1] TomovA.D., Teplenky M.P., Aranovich A.M., Chibirov G.M., Popkov D.A. Roentgenoanatomy of the hip joint following reconstructive intervention in children with spastic cerebral palsy. Genij Ortopedii, 2020, vol. 26, no 1, pp. 50-56. DOI 10.18019/1028-4427-202026-1-50-56. (In Russian) 


\section{MATERIAL AND METHODS}

The study included 49 children who had undergone hip reconstructive surgery for hip displacement or dislocation and followed up for at least three years. All CP patients had a spastic movement disorder as an underlying condition. Using the Gross Motor Function Classification System (GMFCS) 30 patients were classified as GMFCS level IV and 19 as GMFCS level V. Depending on indications either DVO standalone $(n=28,44$ joints, mean age at start of treatment $6.98 \pm 2.2$ years $)$ or DVO and AP $(n=21,38$ joints, mean age at start of treatment $7.0 \pm 2.04$ years) were produced for the patients. The surgeries were added by knee level (lengthening of knee flexor muscles) and/or ankle level interventions and foot deformity correction (different modifications of triceps surae lengthening, Grice subtalar arthrodesis, hallux valgus correction) [28]. Comparison of the acetabular angle, the Reimers' index, the acetabular depth ratio (ADR), the Wiberg center-edge angle measured preoperatively, straight after surgery and at 1, 2, 3 years postsurgery using anteroposterior radiographs of the pelvis [29] was produced to identify the impact of DVO or DVO+AP on the development of the hips. Statistical data analysis was performed using the tools of AtteStat 12.0.5 and Microsoft Excel 2016 programs. The data obtained were summarized as means $(\mathrm{M}) \pm$ standard deviations (SD) using descriptive statistical methods. The Spearman Rank correlation and Pearson's chi-square tests were used to evaluate correlations between the variables.

\section{RESULTS}

Table 1 presents changes in radiological parameters $(\mathrm{M} \pm \mathrm{SD})$ after DVO. Progressive decrease in AI was observed within 3 years after DVO as compared to preoperative measurements with slight increase in the Wiberg angle. Table 2 shows changes in radiological parameters $(\mathrm{M} \pm \mathrm{SD})$ after DVO combined with AP.

A tendency towards progressive increase in $\mathrm{AI}$ observed within 3 years following $\mathrm{DVO}+\mathrm{AP}$ was opposed to that in angle parameters measured after DVO. The Wiberg angle was shown to increase at one-year postsurgery followed by stabilization. Both surgical options demonstrated improved radiological and anatomical parameters and their changes within an age-specific normal range indicated to the favorable development of the hips Fig. 1, 2). The mean yearly increase in the Reimers' index was not more than 3 $\%$ after DVO and not more than $2 \%$ after DVO+AP. There was a tendency towards incresae in Wiberg angle at a two-year follow-up of DVO and at a oneyear follow-up of DVO+AP. Both groups showed normal parameters throughout the whole period of postoperative observation.

Absolute and relative changes $(\mathrm{M} \pm \mathrm{SD})$ in the angles measured postoperatively in both groups are presented in Tables 3-5. Absolute and relative changes in the AI during postoperative acetabulum reconstruction are thought to demonstrate normalization of the hip parameters. The Reimers' index has been shown to increase slightly and evaluated as a positive prognostic factor.

Table 1

Changes in radiological parameters $(\mathrm{M} \pm \mathrm{SD})$ after DVO

\begin{tabular}{|l|c|c|c|c|c|}
\hline \multicolumn{1}{|c|}{ Angle } & Pre-op & Post-op & $\begin{array}{c}\text { One-year } \\
\text { follow-up }\end{array}$ & $\begin{array}{c}\text { Two-year } \\
\text { follow-up }\end{array}$ & $\begin{array}{c}\text { Three-year } \\
\text { follow-up }\end{array}$ \\
\hline AI; $^{\circ}$ & $24.0 \pm 5.3$ & $24.0 \pm 5.3$ & $21.1 \pm 4.1$ & $19.4 \pm 3.6$ & $19.7 \pm 4.1$ \\
\hline Reimers; \% & $46.8 \pm 22.5$ & $6.6 \pm 8.5$ & $7.8 \pm 8.4$ & $11.6 \pm 9.2$ & $14.3 \pm 10.2$ \\
\hline ADR & $4.6 \pm 0.9$ & $4.6 \pm 0.9$ & $4.4 \pm 0.8$ & $4.1 \pm 0.8$ & $3.9 \pm 1.3$ \\
\hline Wiberg; $^{\circ}$ & - & $23.3 \pm 6.4$ & $26.1 \pm 6.5$ & $28.6 \pm 5.9$ & $28.3 \pm 6.8$ \\
\hline
\end{tabular}

Table 2

Changes in radiological parameters $(\mathrm{M} \pm \mathrm{SD})$ after $\mathrm{DVO}+\mathrm{AP}$

\begin{tabular}{|l|c|c|c|c|c|}
\hline \multicolumn{1}{|c|}{ Angle } & Pre-op & Post-op & $\begin{array}{c}\text { One-year } \\
\text { follow-up }\end{array}$ & $\begin{array}{c}\text { Two-year } \\
\text { follow-up }\end{array}$ & $\begin{array}{c}\text { Three-year } \\
\text { follow-up }\end{array}$ \\
\hline AI; ${ }^{\circ}$ & $34.2 \pm 25.3$ & $16.7 \pm 3.9$ & $16.8 \pm 3.9$ & $16.9 \pm 3.4$ & $17.2 \pm 3.1$ \\
\hline Reimers; \% & $73.4 \pm 23.4$ & $3.5 \pm 8.1$ & $3.4 \pm 6.8$ & $7.4 \pm 7.7$ & $8.3 \pm 6.9$ \\
\hline ADR & $5.6 \pm 1.4$ & $4.1 \pm 0.97$ & $4.05 \pm 0.9$ & $3.8 \pm 0.6$ & $3.7 \pm 0.9$ \\
\hline Wiberg; $^{\circ}$ & - & $26.8 \pm 8.9$ & $29.3 \pm 7.1$ & $28.6 \pm 5.7$ & $29.3 \pm 4.97$ \\
\hline
\end{tabular}



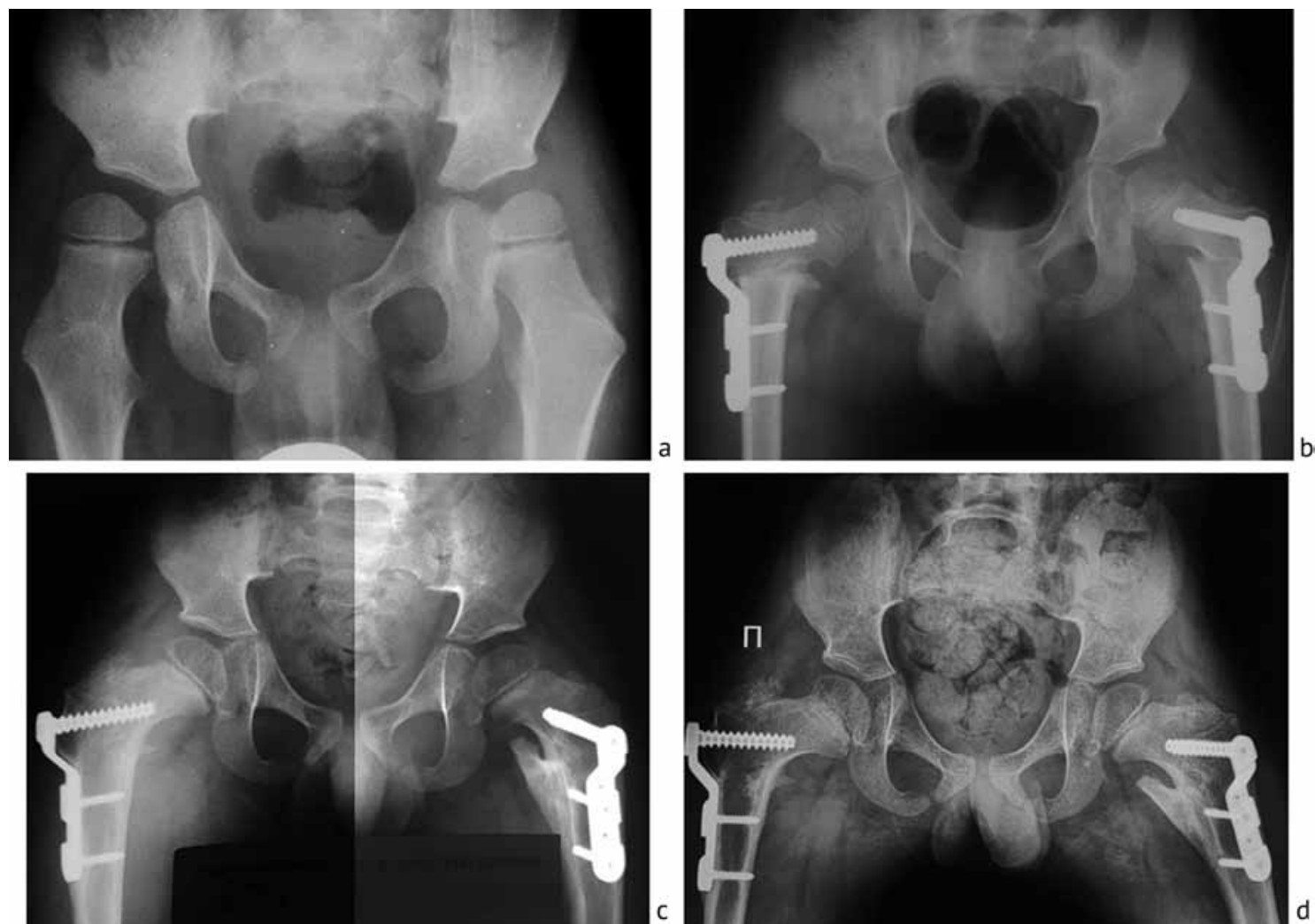

Fig. 1 Anteroposterior radiographs of the pelvis of a 5-yo patient M. showing development of the hip joints following DVO: (a) preop Reimers' index of $41 \%$ on the right and $32 \%$ on the left; $\mathrm{AI} 25^{\circ}$ on the right and AI $28^{\circ}$ on the left; ADR 3.9 on the right and 4.0 on the left; $(\boldsymbol{b})$ postoperative Reimers' index of $7 \%$ on the right and $23 \%$ on the left; AI $25^{\circ}$ on the right and $28^{\circ}$ on the left; ADR 3.9 on the right and 4.0 on the left; Wiberg angle measuring $21^{\circ}$ on the right and $18^{\circ}$ on the left; (c) Reimers' index of $10 \%$ on the right, $17 \%$ on the left; $\mathrm{AI} 15^{\circ}$ on the right and $\mathrm{AI} 20^{\circ}$ on the left; ADR 4.3 on the right and 4.6 on the left; Wiberg angle $24^{\circ}$ on the right and $19^{\circ}$ on the left at one-year follow-up; (d) Reimers' index of $9 \%$ on the right and $10 \%$ on the left; $\mathrm{AI} 17^{\circ}$ on the right and AI $16^{\circ}$ on the left; ADR 4.2 on the right and 4.1 on the left; Wiberg angle $23^{\circ}$ on the right and $21^{\circ}$ on the left at three-year follow-up
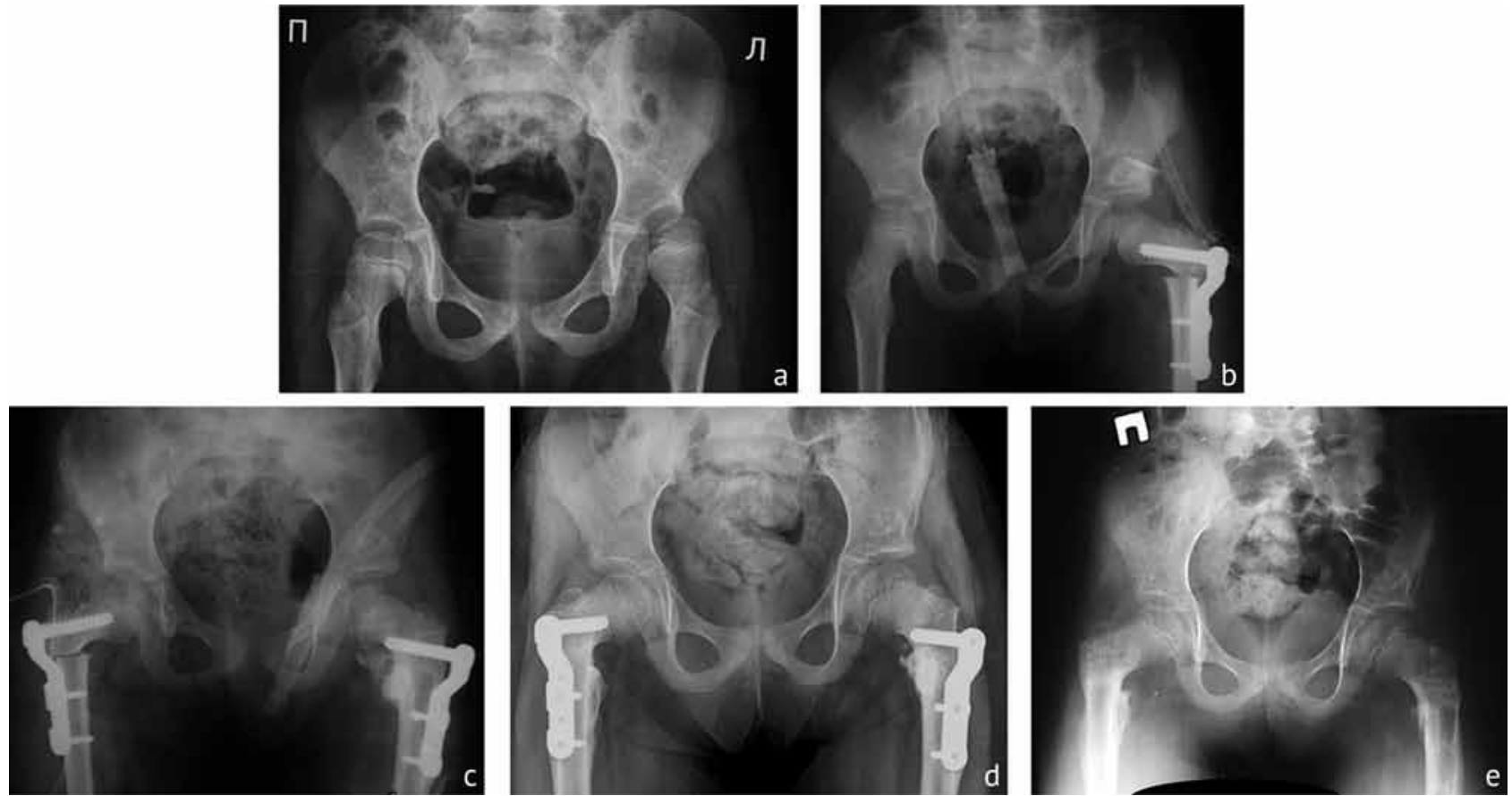

Fig. 2 Anteroposterior radiographs of the pelvis of a 6-yo patient S. showing development of the left hip joint following DVO+AP: (a) pre-op Reimers' index of $49 \%$; AI 40 ; ADR 6.3; (b) postoperative Reimers' index of $0 \%$; AI 10 $0^{\circ}$; ADR 5.0; Wiberg angle measuring $38^{\circ}$; (c) Reimers' index of $0 \%$; AI $10^{\circ}$; ADR 5.1; Wiberg angle $40^{\circ}$ at one-year follow-up; (d) Reimers' index of $0 \%$; AI $12^{\circ}$; ADR 4.1; Wiberg angle $37^{\circ}$ at two-year follow-up; (e) Reimers' index of $0 \%$; AI $11^{\circ}$; ADR 4.3; Wiberg angle $36^{\circ}$ at threeyear follow-up; development of the right hip joint following DVO+AP: $(\boldsymbol{a}),(\boldsymbol{b})$ pre-op Reimers' index of $6 \%$; AI $13^{\circ}$; ADR 4.2; (c) postoperative projectional neck-to-shaft angle of $113^{\circ}$; Reimers' index of $0 \%$; AI $13^{\circ}$; ADR 4.1; Wiberg angle measuring $34^{\circ}$; (d) Reimers' index of $0 \%$; AI $11^{\circ}$; ADR 4.1; Wiberg angle $35^{\circ}$ at one-year follow-up; $(\boldsymbol{e})$ Reimers' index of $0 \%$; AI $11^{\circ}$; ADR 4.3; Wiberg angle $36^{\circ}$ at two-year follow-up; (e) Reimers' index of $0 \%$; AI $11^{\circ}$; ADR 4.3; Wiberg angle $36^{\circ}$ at three-year follow-up 
Postoperative changes in the AI

\begin{tabular}{|l|c|c|c|c|c|c|}
\hline \multirow{2}{*}{ Group } & \multicolumn{3}{|c|}{ Absolute changes; $^{\circ}$} & \multicolumn{3}{c|}{ Relative changes; \% } \\
\cline { 2 - 7 } & 1 year & 2 years & 3 years & 1 year & 2 years & 3 years \\
\hline DVO & $-2.9 \pm 4.4$ & $-4.9 \pm 5.7$ & $-4.9 \pm 4.8$ & $-0.6 \pm 17.3$ & $-16.2 \pm 23.6$ & $-17.5 \pm 20.5$ \\
\hline DVO + AP & $0.13 \pm 3.1$ & $-0.3 \pm 2.9$ & $0.5 \pm 2.6$ & $3.1 \pm 23.7$ & $0.9 \pm 20.7$ & $6.3 \pm 17.8$ \\
\hline
\end{tabular}

Table 4

Postoperative changes in the Reimers' index

\begin{tabular}{|l|c|c|c|}
\hline \multirow{2}{*}{ Group } & \multicolumn{3}{|c|}{ Absolute changes; \% } \\
\cline { 2 - 4 } & 1 year & 2 years & 3 years \\
\hline DVO & $4.2 \pm 9.2$ & $5.4 \pm 11.4$ & $6.2 \pm 9.6$ \\
\hline DVO + AP & $-0.2 \pm 7.6$ & $3.9 \pm 9.4$ & $3.2 \pm 11.04$ \\
\hline
\end{tabular}

Table 5

Postoperative changes in the Wiberg angle

\begin{tabular}{|l|c|c|c|c|c|c|}
\hline \multirow{2}{*}{ Group } & \multicolumn{3}{|c|}{ Absolute changes; $^{\circ}$} & \multicolumn{3}{c|}{ Relative changes; \% } \\
\cline { 2 - 7 } & 1 year & 2 years & 3 years & 1 year & 2 years & 3 years \\
\hline DVO & $2.8 \pm 4.7$ & $5.1 \pm 5.07$ & $3.9 \pm 5.4$ & $15.9 \pm 26.8$ & $26.1 \pm 28.7$ & $20.3 \pm 26.0$ \\
\hline DVO + AP & $2.5 \pm 5.3$ & $1.8 \pm 7.2$ & $4.9 \pm 8.1$ & $18.1 \pm 33.2$ & $23.6 \pm 70.2$ & $17.8 \pm 27.95$ \\
\hline
\end{tabular}

Absolute and relative changes in the Wiberg angle as an integrated index for the development of the hip joint after eliminated displacement/dislocation of the hip indicated to maximal remodeling following DVO at two-year follow-up and mild remodeling following DVO combined with AP at two-to-three-year followup. The Spearman Rank correlation test showed strength of relationship between relative changes in the hip angles and the patient's age at surgery for the AI following DVO at three-year follow-up $(0.461, \mathrm{p}=$ $0.964)$ and for the Wiberg angle at three-year followup $(-0.445, \mathrm{p}=0.978)$. There were no statistically significant differences between the patient's age at surgery and the extent of remodeling of the hip evaluated with radiological and anatomical parameters following standard high-technology surgical interventions. The Spearman Rank correlation test showed strength of «AI - Wiberg angle» relationship presented in Table 6.

Table 6

Postoperative «AI - Wiberg angle» correlation

\begin{tabular}{|l|c|c|}
\hline Follow-up & DVO & DVO + AP \\
\hline 1 year & $-0.461(\mathrm{p}=0.999)$ & $-0.718(\mathrm{p}=0.999)$ \\
\hline 2 years & $-0.479(\mathrm{p}=0.998)$ & $-0.676(\mathrm{p}=0.999)$ \\
\hline 3 years & $-0.580(\mathrm{p}=0.991)$ & $-0.735(\mathrm{p}=0.999)$ \\
\hline
\end{tabular}

The «AI - Wiberg angle» correlation was found to be statistically significant on the Chaddock scale showing reverse moderate, evident profile following DVO. High reverse strength of correlation was shown to be statistically significant at one- and threeyear follow-up. This sort of correlation facilitated beneficial development of the operated hips at a long term following reconstructive interventions.

\section{DISCUSSION}

The natural course of orthopaedic complications like displaced/dislocated hip is associated with the mean yearly increase in the Reimer's migration index that can vary in CP patients with different extent of neurological impairment. The annual migration percentage (MP) increase of $10 \%$ in spastic CP was found by Reimers [30], and Terjesen reported a $9.2 \%$ increase in MP in quadriplegics [9]. In patients with GMFCS levels I, II, III, IV and V, MP increased by $0.2 \% / y e a r, 1.2 \% / y e a r, 1.3 \% / y e a r, 3.9 \% / y e a r$ and $9.5 \%$ year, respectively, according to Terjesen. An annual increase in MP of more than $4 \%$ (Terjesen [9]), 6-7 \% (Soo et al. [31] и Connelly et al. [32]) can be associated with hip dislocation. In our opinion, 
MP is important for postoperative prognosis in the development of the hip. Retrospective analysis of short- and long-term outcomes with a mean follow-up of 6.9 years performed by McNerney et al. indicated to changes in MP from preoperative $66 \%$ to MP of $5 \%$ postsurgery with slight increase in MP to $11 \%$ at a long-term follow-up [10]. The AI changed from $26^{\circ}$ to $13^{\circ}$ at a short term and to $11^{\circ}$ at a longer term. Kalen et al. reported improvements in the mean MP from $84 \%$ to $8 \%$ at a short term and to $14 \%$ at a long term in the retrospective analysis with a mean follow-up of 56 months [33]. Jozwiak et al. reported adequate correction of radiological parameters in 25 CP patients (30 hip joints) with changes in the AI from $22^{\circ}$ до $23^{\circ}$, MP from $11 \%$ to $23 \%$ and Wiberg angle from $16^{\circ}$ to $23^{\circ}$ at a long term [18]. Reidy K. et al. also reported on changes in MP from preoperative $63.6 \%$ to postoperative $2.7 \%$ at a short term, and to $9.7 \%$ at a longer term [20].

In our series, normal relationship between the femoral head and acetabulum persisted at a long-term follow-up. The parameters evaluating acetabular morphology (Wiberg angle, AI and ADR) were shown to improve or remain stable. The mean annual increase in the Reimers' index was not more than $3 \%$ after DVO and not more than $2 \%$ following DVO and AP. Bayusentono et al. found that the postoperative MP increased by $2.0 \%$ per year in patients with GMFCS level IV and by $3.5 \%$ per year in those with level V was associated with stabilization of other radiological parameters of coxometry with no recurrence of displaced/dislocated hips reported [19]. No recurrence of displaced/dislocated hips was observed in our series at three-year follow-up. Continuous physical postural management programs have been shown to play a role in passive verticalization of patients with severe CP to expedite axial loads to lower limbs preventing hip dislocation and creating proper conditions for the development of the hip joint [13, 24, 27]. Our findings suggest that singleevent multilevel surgery involving hip reconstruction can also be practical to facilitate comprehensive postural management programs for children with $\mathrm{CP}$ to enhance participation and activity postsurgery. In our series, progressive decrease in the AI compared to postoperative values with increase in Wiberg angle was observed over the three-year follow-up period in the patients who underwent standalone DVO. An opposite tendency towards progressive increase in the AI reaching normal age-specific values was noted over the three-year follow-up period in the patients who underwent DVO + AP versus scenario observed with standalone DVO. Either way, both reconstructive options were shown to ensure normal radiological and anatomical parameters and the subsequent changes within age-specific normal range facilitating beneficial development of the hip joints.

The «AI - Wiberg angle» correlation was found to be statistically significant showing reverse moderate, evident profile following DVO. High reverse strength of correlation was shown to be statistically significant for combined interventions of DVO and AP. This sort of correlation facilitated beneficial development of the operated hips at a long term following reconstructive interventions. Moderate correlation was observed in changed AI values after DVO at 3 years postsurgery and changes in the Wiberg angle at three-year observation comparing relative measurement changes and the age when surgery was performed. Age appeared to have a minor effect on the development of the hip following multilevel procedures produced for the cohort of patients.

\section{CONCLUSION}

Appropriate conditions should be provided for normal development of the hip following surgical elimination of hip dislocation using growthremaining potential and remodeling the articular ends. Single-event multilevel surgery involving hip reconstruction and addressing knee and ankle contractures is practical for providing favorable conditions for postural management and passive verticalization of patients to maintain axial loading on the limbs. 


\section{REFERENCES}

1. Cooke P.H., Cole W.G., Carey R.P. Dislocation of the hip in cerebral palsy. Natural history and predictability. J. Bone Joint Surg. Br., 1989, vol. 71, no. 3, pp. 441-446.

2. Cooperman D.R., Bartucci E., Dietrick E., Millar E.A. Hip dislocation in spastic cerebral palsy: long-term consequences. J. Pediatr. Orthop., 1987, vol. 7, no. 3, pp. 268-276.

3. Valencia F.G. Management of hip deformities in cerebral palsy. Orthop. Clin. North Am., 2010, vol. 41, no. 4, pp. 549-559. DOI: 10.1016/j.ocl.2010.07.002.

4. Morton R.E., Scott B., McClelland V., Henry A. Dislocation of the hips in children with bilateral spastic cerebral palsy, 1985-2000. Dev. Med. Child. Neurol., 2006, vol. 48, no. 7, pp. 555-558.

5. Pritchett J.W. The untreated unstable hip in severe cerebral palsy. Clin. Orthop. Relat. Res., 1983, no. 173, pp. 169-172.

6. Mc Manus V., Corcoran P., Perry I.J. Participation in everyday activities and quality of life in pre-teenage children living with cerebral palsy in South West Ireland. BMC Pediatr., 2008, vol. 8, pp. 50. DOI: 10.1186/1471-2431-8-50.

7. Viehweger E., Robitail S., Rohon M.A., Jacquemier M., Jouve J.L., Bollini G., Simeoni M.C. Measuring quality of life in cerebral palsy children. Ann. Readapt. Med. Phys., 2008, vol. 51, no. 2, pp. 119-137. DOI: 10.1016/j.annrmp.2007.12.002.

8. Brooks J., Day S., Shavelle R., Strauss D. Low weight, morbidity, and mortality in children with cerebral palsy: new clinical growth charts. Pediatrics, 2011, vol. 128, no. 2, pp. e299-e307. DOI: 10.1542/peds.2010-2801.

9. Terjesen T. The natural history of hip development in cerebral palsy. Dev. Med. Child. Neurol., 2012, vol. 54, no. 10, pp. 951-957. DOI: $10.1111 / \mathrm{j} .1469-749.2012 .04385 . x$.

10.McNerney N.P., Mubarak S.J., Wenger D.S. One-stage correction of the dysplastic hip in cerebral palsy with the San Diego acetabuloplasty: results and complications in 104 hips. J. Pediatr. Orthop., 2000, vol. 20, no. 1, pp. 93-103.

11.Pountney T., Green E.M. Hip dislocation in cerebral palsy. BMJ, 2006, vol. 332, no. 7544, pp. 772-775.

12.Sankar W.N., Spiegel D.A., Gregg J.R., Sennett B.J. Long-term follow-up after one-stage reconstruction of dislocated hips in patients with cerebral palsy. J. Pediatr. Orthop., 2006, vol. 26, no. 1, pp. 1-7.

13.Hägglund G., Andersson S., Düppe H., Lauge-Pedersen H., Nordmark E., Westbom L. Prevention of dislocation of the hip in children with cerebral palsy. The first ten years of a population-based prevention programme. J. Bone Joint Surg. Br., 2005, vol. 87, no. 1, pp. 95-101.

14.Gose S., Sakai T., Shibata T., Murase T., Yoshikawa H., Sugamoto K. Morphometric analysis of acetabular dysplasia in cerebral palsy: three-dimensional CT study. J. Pediatr. Orthop., 2009, vol. 29, no. 8, pp. 896-902. DOI: 10.1097/BPO.0b013e3181c0e957.

15.Popkov D., Journeau P., Popkov A. Comparative study on results of reconstructive surgery in 45 hip joints of 25 children with cerebral palsy. Eur. Orthop. Traumatol., 2014, vol. 5, no. 1. P. 57-63.

16.Mallet C., Ilharreborde B., Presedo A., Khairouni A., Mazda K., Penneçot G.F. One-stage hip reconstruction in children with cerebral palsy: long-term results at skeletal maturity. J. Child. Orthop., 2014, vol. 8, no. 3, pp. 221-228. DOI:10.1007/s11832-014-0589-9.

17.Davids J.R. Management of Neuromuscular Hip Dysplasia in Children With Cerebral Palsy: Lessons and Challenges. J. Pediatr. Orthop., 2018, vol. 38, no. Suppl. 1, pp. S21-S27. DOI: 10.1097/BPO.0000000000001159.

18.Jóźwiak M., Marciniak W., Piontek T., Pietrzak S. Dega's transiliac osteotomy in the treatment of spastic hip subluxation and dislocation in cerebral palsy. J. Pediatr. Orthop., 2000, vol. 9, no. 4, pp. 257-264.

19.Bayusentono S., Choi Y., Chung C.Y., Kwon S.S., Lee K.M., Park M.S. Recurrence of hip instability after reconstructive surgery in patients with cerebral palsy. J. Bone Joint Surg. Am., 2014, vol. 96, no. 18, pp. 1527-1534. DOI:10.2106/JBJS.M.01000.

20.Reidy K., Heidt C., Dierauer S., Huber H. A balanced approach for stable hips in children with cerebral palsy: a combination of moderate VDRO and pelvic osteotomy. J. Child. Orthop., 2016, vol. 10, no. 4, pp. 281-288. DOI: 10.1007/s11832-016-0753-5.

21.Mubarak S.J., Valencia F.G., Wenger D.R. One-stage correction of the spastic dislocated hip. Use of pericapsular acetabuloplasty to improve coverage. J. Bone Joint Surg. Am., 1992, vol. 74, no. 9, pp. 1347-1357.

22.Krebs A., Strobl W.M., Grill F. Neurogenic hip dislocation in cerebral palsy: quality of life and results after hip reconstruction. $J$. Child. Orthop., 2008, vol. 2, no. 2, pp. 125-131. DOI: 10.1007/s11832-008-0080-6.

23.Larsson M., Hägglund G., Wagner P. Unilateral varus osteotomy of the proximal femur in children with cerebral palsy: a five-year follow-up of the development of both hips. J. Child. Orthop., 2012, vol. 6, no. 2, pp. 145-151. DOI: 10.1007/s11832-012-0401-7.

24.Gough M. Continuous postural management and the prevention of deformity in children with cerebral palsy: an appraisal. Dev. Med. Child. Neurol., 2009, vol. 51, no. 2, pp. 105-110. DOI: 10.1111/j.1469-8749.2008.03160.x.

25.McGinley J.L., Dobson F., Ganeshalingam R., Shore B.J., Rutz E., Graham H.K. Single-event multilevel surgery for children with cerebral palsy: a systematic review. Dev. Med. Child. Neurol., 2012, vol. 54, no. 2, pp. 117-128. DOI: 10.1111/j.14698749.2011.04143.x.

26.Popkov D.A., Zmanovskaia V.A., Gubina E.B., Leonchuk S.S., Butorina M.N., Pavlova O.L. Rezultaty mnogourovnevykh odnomomentnykh ortopedicheskikh operatsii i rannei reabilitatsii v komplekse s botulinoterapiei u patsientov so spasticheskimi formami tserebralnogo paralicha [Results of multilevel single-stage orthopedic surgeries and early rehabilitation in combination with botulinum therapy in patients with cerebral palsy spastic forms]. Zhurnal Nevrologii i Psikhiatrii im. S.S. Korsakova, 2015, vol. 115, no. 4, pp. 41-48. (in Russian)

27.Paleg G., Livingstone R. Outcomes of gait trainer use in home and school settings for children with motor impairments: a systematic review. Clin. Rehabil., 2015, vol. 29, no. 11, pp. 1077-1091. DOI: 10.1177/0269215514565947.

28.Tomov A.D., Diachkov K.A., Popkov D.A. Kliniko-rentgenologicheskie rezultaty mnogourovnevykh operativnykh vmeshatelstv pri podvyvikhe i vyvikhe bedra u detei s DTsP [Clinical and radiographic results of multilevel surgical interventions for hip subluxation and dislocation in children with cerebral palsy]. Genij Ortopedii, 2018, vol. 24, no. 1, pp. 24-32. (in Russian) DOI: 10.18019/10284427-2018-24-1-24-32.

29.Shevtsov V.I., Makushin V.D., Teplenky M.P., Loginova N.G. Rentgenoanatomicheskaia diagnostika displazii vertluzhnoi vpadiny $\mathrm{u}$ detei [The roentgen-and-anatomic diagnostics of acetabular dysplasia in children]. Genij Ortopedii, 2006, no. 1, pp. 115-119. (in Russian) 
Genij Ortopedii, Vol. 26, no 1, 2020

30.Reimers J. The stability of the hip in children. A radiological study of the results of muscle surgery in cerebral palsy. Acta Orthop. Scand. Suppl., 1980, vol. 184, pp. 1-100.

31.Soo B., Howard J.J., Boyd R.N., Reid S.M., Lanigan A., Wolfe R., Reddihough D., Graham H.K. Hip displacement in cerebral palsy. J. Bone Joint Surg. Am., 2006, vol. 88, no. 1, pp. 121-129. DOI: 10.2106/JBJS.E.00071.

32.Connelly A., Flett P., Graham H.K., Oates J. Hip surveillance in Tasmanian children with cerebral palsy. J. Paediatr. Child. Health, 2009, vol. 45, no. 7-8, pp. 437-443. DOI: 10.1111/j.1440-1754.2009.01534.x.

33.Kalen V., Bleck E.E. Prevention of spastic paralytic dislocation of the hip. Dev. Med. Child. Neurol., 1985, vol. 27, no. 1, pp. $17-24$.

34.Hägglund G., Lauge-Pedersen H., Persson M. Radiographic threshold values for hip screening in cerebral palsy. J. Child. Orthop., 2007, vol. 1, no. 1, pp. 43-47. DOI: 10.1007/s11832-007-0012-x.

35.Clarke A.M., Redden J.F. Management of hip posture in cerebral palsy. J. R. Soc. Med., 1992, vol. 85, no. 3, pp. $150-151$.

Received: 11.06.2019

\section{Information about the authors:}

1. Ahmed D. Tomov, M.D., National Ilizarov Medical Research Centre for Orthopaedics and Traumatology, Kurgan, Russian Federation 2. Mikhail P. Teplenky, M.D., Ph.D., National Ilizarov Medical Research Centre for Orthopaedics and Traumatology, Kurgan, Russian Federation 3. Anna M. Aranovich, M.D., Ph.D., Professor,

National Ilizarov Medical Research Centre for Orthopaedics and Traumatology, Kurgan, Russian Federation

4. Georgy M. Chibirov, M.D., Russian Ilizarov Scientific Centre for Restorative Traumatology and Orthopaedics, Kurgan, Russian Federation 5. Dmitry A. Popkov, M.D., Ph.D., Professor of RAS, Russian Ilizarov Scientific Centre for Restorative Traumatology and Orthopaedics, Kurgan, Russian Federation, Email: dpopkov@mail.ru 